\title{
cMET as a potential therapeutic target in gastric cancer (Review)
}

\author{
LISONG TENG and JUNLU
}

\author{
Department of Surgical Oncology, The First Affiliated Hospital, School of Medicine, \\ Zhejiang University, Hangzhou, Zhejiang 310000, P.R. China
}

Received July 24, 2013; Accepted October 16, 2013

DOI: $10.3892 /$ ijmm.2013.1531

\begin{abstract}
Gastric cancer is one of the most common malignancies worldwide. Despite improvements in surgery and chemotherapy, the outcomes in patients with advanced gastric cancer remain poor. cMET is a member of the receptor tyrosine kinase family, and plays a key role in tumor survival, growth, angiogenesis and metastasis. cMET overexpression and/or gene amplification occurs in a significant proportion of gastric cancers. cMET is associated with a high tumor stage and poor prognosis. Several cMET inhibitors have been investigated in clinical trials, and the initial results are encouraging. It has become increasingly apparent that cMET is a promising therapeutic target in gastric cancer. In this review, we summarize the development of cMET inhibitors in the preclinical and clinical environment. In addition, we discuss the challenges of cMETtargeted therapy in gastric cancer and explore possible solutions.
\end{abstract}

\section{Contents}

1. Introduction

2. The cMET pathway

3. The role of cMET in gastric cancer

4. The development of cMET inhibitors in gastric cancer

5. Monoclonal antibodies to HGF

6. Monoclonal antibodies to cMET

7. Tyrosine kinase inhibitors of cMET

8. Resistance to cMET inhibitors

9. Conclusion

\section{Introduction}

Gastric cancer (GC) is the fourth most commonly diagnosed cancer and the second major cause of cancer-related mortality

Correspondence to: Dr Lisong Teng, Department of Surgical Oncology, The First Affiliated Hospital, School of Medicine, Zhejiang University, 79 Qingchun Road, Hangzhou, Zhejiang 310000, P.R. China

E-mail: 11218203@zju.edu.cn

Key words: cMET, gastric cancer, targeted therapy, cMET inhibitors, drug resistance worldwide $(1,2)$. Despite improvements in surgery and chemotherapy, the outcomes in patients with advanced gastric cancer remain poor, with a five-year survival rate of $<20 \%$ (3).

Over the past decade, targeted therapies have greatly improved the outcome of a number of malignancies, including breast, colorectal and lung cancer. However, less progress has been made with regard to gastric cancer. The Trastuzumab for Gastric Cancer (ToGA) study, investigating the effectiveness of trastuzumab in human epidermal growth factor receptor 2 (HER2; ERBB2)-positive advanced gastric or gastrooesophageal junction (GEJ) cancer (4), represents a milestone in the targeted therapy of gastric cancer. Moreover, a recent study developed a genomic molecular map of gastric cancer and suggested that collectively $37 \%$ of cases may be potentially treatable by receptor tyrosine kinase (RTK)/RAS directed therapies (5).

Similar to HER2, cMET is another member of the RTK family, and plays a key role in tumor survival, growth, angiogenesis and metastasis (6-10). A significant proportion of gastric cancers harbor cMET overexpression and/or gene amplification $(11,12)$, and the aberrant signaling of cMET pathways in gastric cancer has been shown to correlate with a high tumor stage and poor prognosis $(11,13)$. The alternative activation of the cMET pathway is considered to be an important mechanism responsible for resistance therapeutics targeting HER family members, such as HER2 and epidermal growth factor receptor (EGFR) (14,15). Recently, several cMET inhibitors have been investigated in clinical trials, and the initial results are encouraging $(16,17)$. cMET is emerging as a promising therapeutic target in gastric cancer, and may provide a potential approach to overcoming resistance to other agents in targeted therapy.

Although a number of review articles have focused on the role of cMET in various malignancies, there is a lack of data on its role in gastric cancer. Therefore, a greater understanding of the role of cMET in gastric cancer is required.

In this review, we assess the role of cMET in gastric cancer, summarize the preclinical and clinical trials of cMET inhibitors, and discuss the challenges of cMET targeted therapy. Finally, we present possible solutions, including the exploration of biomarkers for population selection and drug response assessment, and the establishment of patient-derived human tumor tissue (PDTT) xenograft models for drug sensitivity screening.

\section{The cMET pathway}

cMET was first identified in 1984 in a human osteogenic sarcoma cell line treated with the carcinogen, N-methyl- 


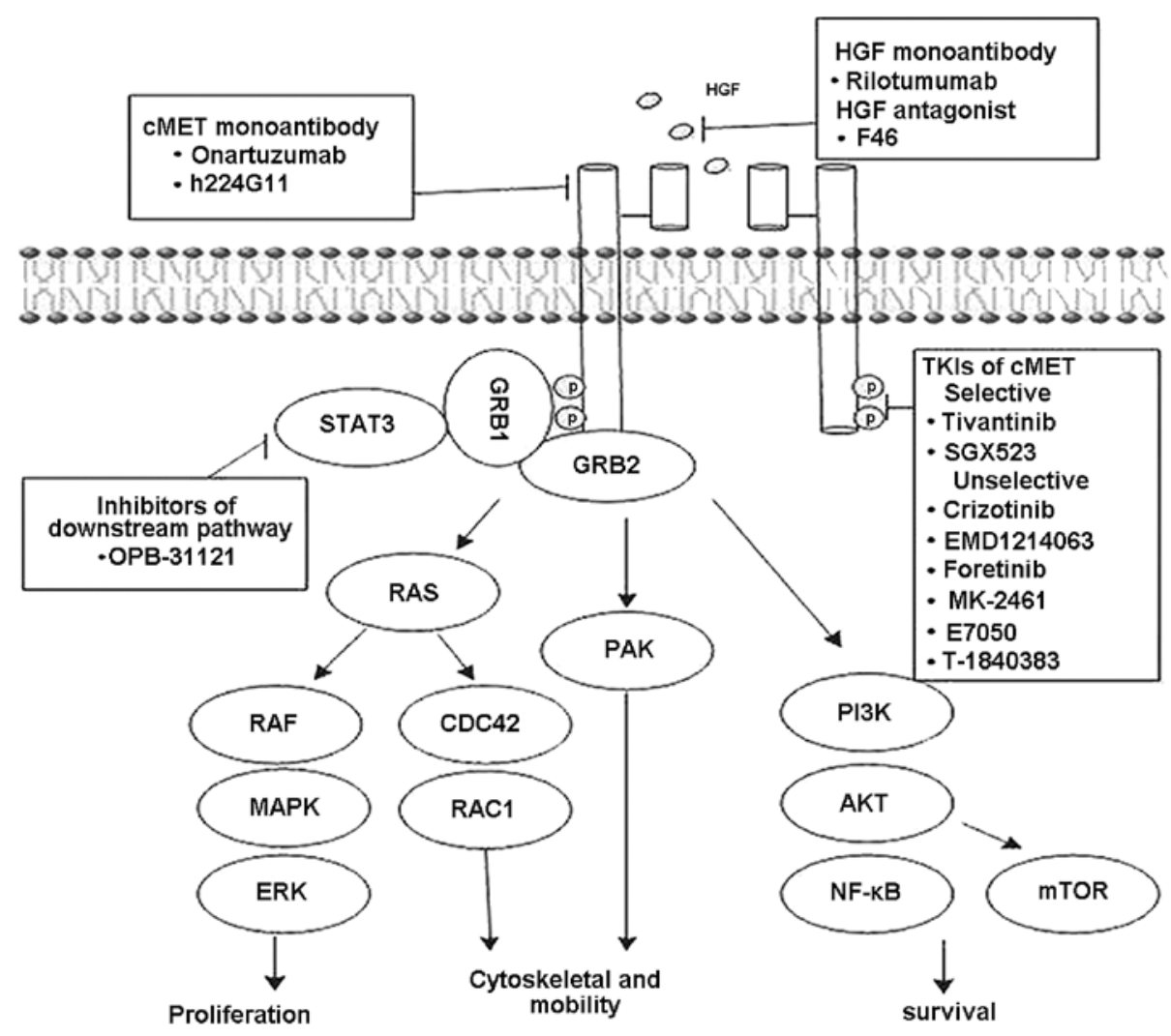

Figure 1. Simplified schematic diagram of the cMET pathway and the main strategies for targeted therapy. Binding of hepatocyte growth factor (HGF)/scatter factor (SF) to cMET leads to the activation of multisteps in the signal transduction cascade, which regulates cell proliferation, survival, cytoskeletal and mobility signals (24-29). cMET signaling can be disrupted at different levels, from the cMET receptor to the downstream pathway. CDC42, RAC1-cell division control protein 42; GRB2, growth factor receptor-bound protein 2; GAB1, GRB2-associated protein 1; PAK, p21-activated kinase; STAT3, signal transducer and activator of transcription 3.

$\mathrm{N}$-nitronitrosoguanidine (18), by a genomic rearrangement that fused the sequence from the translocated promoter region (TRP) locus on chromosome 1 to a sequence from MET on chromosome 7 (19). A subsequent study revealed that the encoded protein was an RTK (20).

Both hepatocyte growth factor (HGF) and scatter factor (SF), are the ligands of cMET (21). HGF was originally identified as a liver mitogen, while SF was recognized as a fibroblast-derived modulators of epithelial cell mobility, then they were found to be identical $(22,23)$. Binding of HGF/SF to cMET leads to receptor homodimerization and tyrosine residue phosphorylation, recruitment of adaptor and effector proteins, which ultimately triggers downstream activation of the RAS/mitogen-activated protein kinase (MAPK), phosphoinositide 3-kinase (PI3K)/AKT, signal transducer and activator of transcription (STAT), Ras-related C3 botulinum toxin substrate $1(\mathrm{RACl})$-cell division cycle $42(\mathrm{CDC} 42)$ and p21 activated protein kinase (PAK) pathways (Fig. 1) (24-29). The cMET pathway can be modulated by cell surface molecules, such as EGFR, ERBB2 and insulin-like growth factor-1 (29-31). Under normal conditions, the cMET signaling pathway is essential for a spectrum of physiological processes, such as embryonic development, organ morphogenesis and wound healing (32-36). However, the dysregulation of the cMET pathway plays a causal role in tumor survival, growth, angiogenesis and metastasis (6-10).

\section{The role of cMET in gastric cancer}

The cMET pathway can be oncogenic and is activated by multiple mechanisms including, gene amplification, gene mutation, protein overexpression and ligand-dependent autocrine and paracrine, receptor crosstalk $(10,28)$. The role of cMET in gastric tumorigenesis was first identified in the human gastric tumor cell line, GTL-16 (37). The overexpression of TPR-MET RNA was detected in superficial gastritis lesions with hyperplasia of glandular neck cells, suggesting the possible involvement of this oncogene at an early stage of gastric tumorigenesis (38). Similar results were reported in another study (39).

cMET protein overexpression, as well as gene amplification and mutation have been detected in gastric cancer tissues and cell lines. Protein overexpression and gene amplification can be determined by immunohistochemistry (ICH) and RT-PCR/ fluorescence in situ hybridization (FISH), respectively. Among the retrospective studies $(5,11-13,40-46)$ (Table I), the increased expression of cMET was detected in approximately $43 \%$ of patients with gastric cancer, while gene amplification was detected in almost $12 \%$ of patients. Protein overexpression and/or gene amplification significantly correlated with the depth of tumor invasion and metastasis $(11,13,45)$ and poor prognosis $(5,11-13,40,43-46)$. Based on available evidence, it can be inferred that gene amplification is likely to be more 
Table I. Overexpression and amplification status of cMET in gastric cancer.

\begin{tabular}{|c|c|c|c|c|c|c|c|}
\hline Authors/(Refs.) & Year & $\begin{array}{l}\text { No. of } \\
\text { Patients }\end{array}$ & $\mathrm{OP}(\%)$ & Method & $\mathrm{AP}(\%)$ & Method & $\begin{array}{l}\text { Poor prognostic } \\
\text { marker }\end{array}$ \\
\hline Tsugawa et al (44) & 1998 & 70 & & & 10 & Slot blot hybridization & AP \\
\hline Nakajima et al (11) & 2000 & 128 & 41.6 & $\mathrm{ICH}$ & 10.2 & Southern blot hybridization & OP/AP \\
\hline Park et al (43) & 2000 & 43 & 67 & $\mathrm{ICH}$ & & & NR \\
\hline Tang et al (13) & 2004 & 232 & 68.8 & $\mathrm{ICH}$ & & & OP/AP \\
\hline Retterspitz et al (42) & 2010 & 94 & 50 & $\mathrm{ICH}$ & & & NR \\
\hline Janjigian et al (41) & 2011 & 38 & 63 & $\mathrm{ICH}$ & 0 & FISH & NR \\
\hline Lee et al (12) & 2011 & 482 & & & 21.2 & RT-PCR/FISH & AP \\
\hline Graziano et al (45) & 2011 & 230 & & & 10 & RT-PCR/FISH & AP \\
\hline Lee et al (40) & 2012 & 438 & 23.7 & $\mathrm{ICH}$ & 3.4 & SISH & AP \\
\hline Deng et al (5) & 2012 & 193 & & & 4 & SNP arrays & AP \\
\hline Shi et al (46) & 2012 & 128 & & & 30 & RT-PCR & AP \\
\hline Total & & & 42.8 & & 12.1 & & \\
\hline
\end{tabular}

OP, cMET protein overexpression; AP, gene amplification; IHC, immunohistochemistry; FISH, fluorescence in situ hybridization; SISH, silver in situ hybridization; NR, not reported.

valuable than protein overexpression as a prognostic marker. However, a lack of consistent criteria on the determination of protein overexpression and gene amplification limits the prognostic value of these two markers. Consistent criterion that can evaluate cMET expression and amplification is required.

In gastric cancer, cMET gene mutations appear to be very rare; the majority of cMET mutations have been discovered in papillary renal carcinoma $(47,48)$. A germline missense cMET mutation located at the juxtamembrane domain has been reported in a patient with primary gastric cancer (49). Moreover, the Hs746T gastric cell line harbors a splice site mutation of cMET, causing juxtamembrane domain deletion (50). A large proportion of gastric cancer patients harbor cMET overexpression and/or gene alteration, providing evidence for the key role of cMET in gastric cancer and a rationale for the development of cMET inhibitors.

\section{The development of cMET inhibitors in gastric cancer}

The increased understanding of the cMET pathway has led to the development of cMET inhibitors, which focus on one of the steps in the cMET pathway. Clinical trials investigating monoclonal antibodies and small-molecule inhibitors directed at the cMET axis are currently underway. The initial results of these clinical trials are optimistic; thus, targeting the cMET pathway is becoming a promising therapeutic strategy for gastric cancer. The main strategies include, monoclonal antibodies or antagonists against HGF or cMET, cMET selective or unselective tyrosine kinase inhibitors (TKIs) and downstream pathway inhibitors (Fig. 1 and Table II).

\section{Monoclonal antibodies to HGF}

Rilotumumab (AMG 102) is a fully human monoclonal antibody to $\mathrm{HGF} / \mathrm{SF}$. In vitro and in vivo studies have confirmed the antitumor activity of rilotumumab $(51,52)$. A phase 1 clinical study testing the safety and pharmacokinetics of rilotumumab in
40 patients with refractory advanced solid tumors, demonstrated that rilotumumab was safe and well tolerated, and had a favorable pharmacokinetic profile. A total of 16 of $23(70 \%)$ evaluated patients had a best response of stable disease (SD) with progression-free survival (PFS) ranging from 7.9 to 40 weeks (53).

A multicenter, double-blind phase $1 \mathrm{~b} / 2$ study, assessed rilotumumab in combination with epirubicin, cisplatin and capecitabine (ECX) in 121 advanced or metastatic gastric or esophagogastric junction (EGJ) cancer patients (54). This study reported that the addition of rilotumumab to the chemotherapeutic regimen improved the median PFS from 4.2 to 5.6 months [hazard ratio (HR), $0.64 ; 80 \%$ confidence interval (CI), 0.48-0.85], and the median and overall survival (OS) from 8.9 to 11.1 months (HR, 0.73; 80\% CI, 0.53-1.01). Further analysis of this study (54), revealed that the addition of rilotumumab to the chemotherapeutic regimen in patients with gastric tumors with high cMET expression improved median OS from 5.7 to 11.1 months (HR, 0.29; 95\% CI, 0.11-0.76). Conversely, in patients with low cMET expression, the addition of rilotumumab to chemotherapy was associated with a trend towards an unfavorable OS (HR, 1.84; 95\% CI, 0.78-4.34). In the chemotherapy-only arm, patients with a high cMET expression had a worse OS (HR, 3.22; 95\% CI, 1.08-9.63) than those with a low cMET expression; similar trends were observed with PFS (16).

A phase III study to confirm the efficacy of rilotumumab in advanced gastric and gastroesophageal cancer in patients with high cMET expression is currently ongoing (55). Another phase II trial, assessing [folinic acid (FOL, fluorouracil (F) and oxaliplatin (OX); FOLFOX] alone or in combination with AMG 102 or panitumumab as first-line therapy in patients with advanced gastroesophageal adenocarcinoma, is also currently ongoing (56). In addition to the typical outcome measures, such as PFS, OS, objective response rate and safety, the study has been designed to identify candidate predictive and prognostic biomarkers among functional molecular alterations of the EGFR/RAS/RAF and HGF/cMET pathways. 
Table II. Development of cMET inhibitors in gastric cancer.

\begin{tabular}{|c|c|c|c|c|}
\hline Company & Compound & Type of agent & $\begin{array}{l}\text { Development } \\
\text { phase }\end{array}$ & Initial results \\
\hline Amgen & Rilotumumab & HGF mAb & II and III & $\begin{array}{l}\text { Rilotumumab + CT vs. CT: median PFS } 4.2 \text { months } \\
\text { vs. } 5.6 \text { months; OS } 5.7 \text { months vs. } 11.1 \text { months; } \\
\text { suggest MET expression as predictive biomarker (54). }\end{array}$ \\
\hline Roche & MetMab & cMET mAb & III & $\begin{array}{l}\text { MetMab: a patient with chemo-refractory metastatic } \\
\text { gastric cancer of the liver achieved complete } \\
\text { response lasting for } 2 \text { years by MetMAb } \\
\text { monotherapy (17). Suggesting circulating HGF is } \\
\text { a therapeutic response biomarker. }\end{array}$ \\
\hline $\begin{array}{l}\text { Daiichi } \\
\text { Sankyo }\end{array}$ & Tivantinib & cMET selective TKI & II & $\begin{array}{l}\text { Tivantinib: Median PFS } 43 \text { days, disease control } \\
\text { rate } 36.7 \% \text {. No objective response }(64) \text {. }\end{array}$ \\
\hline Exelixis & Cabozantinib & CMET unselective TIK & II & $\begin{array}{l}\text { Cabozantinib: } 8 / 19 \text { patients SD observed at } 12 \text { weeks, } \\
\text { overall disease control rate } 32 \% \text { at } 12 \text { weeks. } \\
\text { No objective response was observed }(73) \text {. }\end{array}$ \\
\hline Pfizer & Crizotinib & CMET unselective TIK & $\mathrm{I}$ & $\begin{array}{l}\text { Crizotinib: } 2 / 4 \text { patients with MET-amplified } \\
\text { gastroesophageal cancer, tumor shrinkage, } \\
(-30 \text { and }-16 \% \text { ) progression after } 3.7 \text { and } 3.5 \text { months; } \\
\text { MET, EGFR and HER } 2 \text { amplification status } \\
\text { may be evaluable ( } 67) \text {. }\end{array}$ \\
\hline Exelixis & Foretinib & CMET unselective TIK & II & $\begin{array}{l}\text { Foretinib: } 15 / 73 \text { patients SD (median } 3.2 \text { months); } \\
\text { no response observed }(70) \text {. }\end{array}$ \\
\hline Otsuka & OPB-31121 & STAT3 inhibitor & $\mathrm{I}$ & OPB-31121: 1/5 SD patients (>12 months) (75). \\
\hline $\begin{array}{l}\text { EMD } \\
\text { Serono }\end{array}$ & EMD 1214063 & CMET unselective TIK & I & \\
\hline Merck & MK-2461 & CMET unselective TIK & I & \\
\hline Goetsch et al & h224G11 & cMET mAb & Preclinical & \\
\hline SGX & SGX523 & cMET selective TKI & Preclinical & \\
\hline Eliai & E-7050 & CMET unselective TIK & Preclinical & \\
\hline Takeda & T-1840383 & CMET unselective TIK & Preclinical & \\
\hline Samsung & F46 & HGF antagonist & Preclinical & \\
\hline
\end{tabular}

HGF, hepatocyte growth factor; TKI, tyrosine kinase inhibitor; mAb, monoclonal antibody; Samsung, Samsung Advanced Institute of Technology; SGX, SGX Pharmaceuticals; SD, stable disease; PFS, progression-free survival; OS, overall survival; CT, chemotherapy.

\section{Monoclonal antibodies to cMET}

MetMab (onartuzumab) is a monoclonal single-arm humanized immunoglobulin (Ig) G1 antibody directed against cMET. In an in vitro study, onartuzumab was first investigated in the human glioblastoma cell line, U87, suggesting that the antibody may exert tumor inhibitory effects, such as anti-proliferative, antiangiogenic and pro-apoptotic effects (57). MetMab has also been shown to be effective against tumor xenografts (57).

In a phase I clinical trial, a patient with chemo-refractory metastatic gastric cancer achieved a complete response with MetMab monotherapy that lasted for two years. The primary tumor had high cMET gene polysomy, as shown by FISH, and a high cMET expression (2+), as observed by IHC. Intriguingly, HGF serum levels were extremely high prior to treatment and declined precipitously immediately after drug exposure, and remained low, even at the time of widespread recurrence of the disease. This observation suggests that circulating HGF is a biomarker for therapeutic response (17). Similar results have been reported in non-small cell lung cancer (NSCLC); circulating HGF levels were measured as a pharmacodynamic biomarker of onartuzumab activity (58). Other studies using PET with (89)Zr-df-onartuzumab and (76)Br-onartuzumab in gastric carcinoma xenografts showed that the uptake of both tracers significantly correlated with tumor mass and cMET expression and was not affected by the presence of plasma shed cMET (59). 
Currently, a randomized, double-blind, phase II study evaluating the efficacy and safety of onartuzumab in combination with mFOLFOX6 in patients with metastatic HER2-negative gastroesophageal cancer is ongoing (60).

Another currently ongoing phase III study introduced an enrichment biomarker, enrolling patients with metastatic HER2-negative, cMET-positive gastroesophageal cancer (61). The results of clinical trials on potential biomarkers may provide recommendations on patient selection and drug response assessment.

\section{Tyrosine kinase inhibitors of cMET}

Tivantinib is a selective, non-ATP competitive, small-molecule inhibitor of cMET. In vitro and in vivo studies have demonstrated that ARQ-197 inhibits cMET activation in numerous human gastric cancer cell lines and xenografts (62). Recent evidence suggests that tivantinib inhibits microtubule polymerization, in addition to inhibiting cMET; thus, tivantinib exerts its antitumor activity in a manner independent of the cMET status (63). In a single-arm phase II study on Asian patients with previously treated metastatic gastric cancer, 30 patients received tivantinib; cMET gene amplification (5 copies/cell) was observed in four patients (13.3\%), and the disease control rate was $36.7 \%$ (11/30). The median PFS was 43 days (95\% CI, 29.0-92.0). No objective response was observed. Grade 3 or 4 adverse events (AEs) occurred in 13 patients (43.3\%), in whom neutropenia $(n=4)$ and anemia $(n=4)$ were recognized to be drug-related. Only two patients discontinued treatment due to AEs. There were no treatment-related deaths and no new reported AEs. No obvious correlation was identified between treatment outcome and specific biomarkers, including cMET gene amplification, cMET, p-cMET and HGF expression in tumor and serum (64). Currently, a phase I/II trial is recruiting patients to evaluate the response rate of the combination of tivantinib plus FOLFOX as first-line therapy for metastatic gastroesophageal cancer (65).

Crizotinib is an ATP competitive small-molecule inhibitor for cMET and anaplastic lymphoma kinase (ALK), which has shown marked antitumor activity in vitro and in vivo, specifically in gastric cancer cells positive for MET amplification (66). A recent study followed up four patients as part of an expanded phase I cohort study; two of four patients with MET-amplified gastroesophageal cancer treated with crizotinib experienced tumor shrinkage $(-30$ and $-16 \%)$ and experienced progression after 3.7 and 3.5 months. The research group also assessed MET, EGFR and HER2 amplification status using FISH in 489 patients with gastroesophageal cancer. The gene amplification rate of MET, EGFR and HER2 was 2, 4.7 and $8.9 \%$, respectively. The majority $(84 \%)$ of the samples were wild-type for all three genes. Survival analysis in patients with stages III and IV disease revealed that the cMET amplified group had lower survival rates (7.1 months; $\mathrm{P}<0.001)$ than the EGFR amplified group (11.2 months; $\mathrm{P}=0.16)$ and the HER2 amplified group (16.9 months; $\mathrm{P}=0.89)$ when compared with the negative group (16.2 months) (67).

Foretinib (GSK1363089 or XL880) is an oral multikinase inhibitor that primarily targets cMET and vascular endothelial growth factor receptor 2 (VEGFR2). It can prevent tumor growth through a direct effect on tumor cell proliferation and through the inhibition of invasion and angiogenesis mediated by HGF and VEGF receptors (68). In an in vitro study, foretinib appeared effective against gastric cancer cells harboring not only cMET but also FGFR2 amplification (69).

In a phase II study evaluating two dosing schedules of oral foretinib (GSK1363089) in 74 patients with metastatic gastric cancer, the best response was SD in ten (23\%) patients receiving intermittent dosing and five (20\%) receiving daily dosing. SD duration ranged from 1.9 to 7.2 months (median 3.2 months). Of 67 patients with tumor samples, three had cMET amplification, one of whom had SD. Treatment-related AEs occurred in $91 \%$ of patients; the rates of hypertension (35 vs. $15 \%)$ and elevated aspartate aminotransferase levels (23 vs. $8 \%$ ) were higher with intermittent dosing. In both patients with high baseline tumor phospho-MET (p-MET), the p-MET: total MET protein ratio decreased following treatment with foretinib. However, no responses were observed in this patient cohort; this may perhaps be due to the evaluation of a non-molecularly selected population (70). The efficient development of targeted therapies that may only benefit a fraction of patients requires clinical trial designs that use biomarkers to identify sensitive subpopulations (71).

Cabozantinib (XL184) is an orally bioavailable TKI with activity against MET and VEGFR2, AXL, KIT, TIE2, FLT3 and RET signaling. It showed antimetastatic, antitumor and antiangiogenic activity in preclinical models (72). A phase II randomized discontinuation trial of cabozantinib enrolled 397 patients with advanced solid tumors. In the gastric cohort, a total of 21 patients were enroled, 19 patients had evaluable responses. The best response was SD achieved by eight patients, and the overall disease control rate was $32 \%$ at 12 weeks. No objective response was observed (73).

With a better understanding of the role of the cMET pathway in cancer, a number of other cMET inhibitors are currently in development. Some molecules have already been investigated in phase I/II clinical trials in patients with advanced solid tumors, such as OPB-31121 (74,75) MK-2461 (76) and EMD 1214063 (77). Some, including SGX523 (78), T-1840383 (79), F46 (80), E7050 (81) and h224G11 (82), have been shown to exert effects on gastric cell lines and xenografts in preclinical studies (Table II).

\section{Resistance to cMET inhibitors}

The clinical efficacy of targeted therapy is hindered by the emergence of primary and acquired resistance. In the ToGA trial, the addition of trastuzumab to the chemotherapeutic regimen only led to an absolute increase in response rate of $12 \%$ (4), indicating the existence of de novo resistance. Moreover, a large proportion of those patients initially responsive to trastuzumab developed acquired resistance. With the introduction of cMET inhibitors into the clinical setting, the same question cannot be avoided. To date, little is known about the mechanisms responsible for resistance to cMET inhibitors.

An in vitro and in vivo study indicated that gastric cancer tumors bearing constitutive activation of HER family members responded poorly to MET inhibition (83). cMET activation may mediate resistance to EGFR and HER2 in gastric cancer $(14,15)$. Another study observed that the acquisition of a mutation in the MET activation loop (Y1230), destabilized the 
autoinhibitory conformation of MET and abrogated an important aromatic stacking interaction with the inhibitor (84). In a recent study, a cMET-sensitive gastric cancer cell line was chronically exposed to the cMET inhibitor, PF-04217903. As a result, a novel SND1-BRAF fusion was observed and proven to be responsible for the resistance (85).

The RTK family accounts for a high percentage of the potential treatable genomic-targeted map of gastric cancer (5); the crosstalk between RTKs may also play an important role in drug resistance. Moreover, the prolonged exposure of a gastric cancer cell line to TKIs has been shown to lead to amplification and overexpression of wild-type Kras and to overcome the inhibitory effects of cMET TKIs (86). These data suggest that targeting cMET may be crucial to overcoming potential resistance to other agents in targeted therapy. Thus, close attention should be paid to this issue during the development of cMET inhibitors.

\section{Conclusion}

Increasing evidence suggests that cMET plays a key role in the development of gastric cancer. A total of $12.1 \%$ of gastric cancer patients harbor gene amplification and $42.8 \%$ have protein overexpression (Table I). cMET protein overexpression and/or gene amplification have been shown to significantly correlate with the depth of tumor invasion and metastasis and poor prognosis $(11,13)$. cMET inhibitors have been investigated in clinical trials, with encouraging initial results $(16,17)$. On the basis of these findings, cMET is considered to be a promising therapeutic target in gastric cancer.

However, with the rapid development of cMET inhibitors, a number of trials have been published which show less than favorable outcomes $(70,73)$. These results can largely be attributed to a lack of appropriate biomarkers for patient selection and drug response assessment. Moreover, while a proportion of gastric cancers harbor cMET overexpression and/or amplification, it is unclear whether the cMET alteration is acting as an oncogenic driver or a passenger. Recent clinical trials have been designed with molecular alterations of cMET, EGFR/RAS/RAF as biomarkers $(56,61,84)$. Future clinical trials may also assess molecular derangements such as cMET mutation, K-ras amplification, EGFR and HER2 status as predictive markers $(14,15,83,84,86)$.

Drug resistance is another critical issue in the development of cMET inhibitors that needs to be addressed. Combined therapies against different pathways and at different levels may be a feasible approach to settle this issue. PDTT xenograft models, which can reliably mimic disease response in humans, is an ideal platform to study biomarker selection and drug resistance (87). PDTT can be used as a drug sensitivity screening platform and may provide reliable information for the treatment of patients. Several cMET-positive PDTT models have been established to research biomarker selection and drug resistance. Interestingly, alpha-fetoprotein producing gastric cancer (AFPGC) with high cMET expression was found in our PDTT models. Previous studies have also reported a higher frequency of cMET expression in AFPGC compared with advanced gastric cancer (88). We are currently using a PDTT model to investigate whether AFPGC is a special subgroup for cMET.
cMET is a promising target in gastric cancer, and it is important to determine the specific subpopulations that are likely to derive the greatest benefit from cMET inhibition. Therefore, future studies should focus on the exploration of biomarkers to optimize patient selection and drug response assessment.

\section{References}

1. Garcia M, Jemal A, Ward EM, et al: Global Cancer Facts and Figures 2007. GA: American Cancer Society, Atlanta, 2007.

2. Jemal A, Bray F, Center MM, Ferlay J, Ward E and Forman D: Global cancer statistics. CA Cancer J Clin 61: 69-90, 2011.

3. Verdecchia A, Santaquilani M and Sant M: Survival for cancer patients in Europe. Ann Ist Super Sanita 45: 315-324, 2009.

4. Bang YJ, Van Cutsem E, Feyereislova A, et al: Trastuzumab in combination with chemotherapy versus chemotherapy alone for treatment of HER2-positive advanced gastric or gastrooesophageal junction cancer (ToGA): a phase 3, open-label, randomised controlled trial. Lancet 376: 687-697, 2010.

5. Deng N, Goh LK, Wang H, et al: A comprehensive survey of genomic alterations in gastric cancer reveals systematic patterns of molecular exclusivity and co-occurrence among distinct therapeutic targets. Gut 61: 673-684, 2012.

6. Bussolino F, Di Renzo MF, Ziche M, et al: Hepatocyte growth factor is a potent angiogenic factor which stimulates endothelial cell motility and growth. J Cell Biol 119: 629-641, 1992.

7. Zhang YW, Su Y, Volpert OV and Vande Woude GF: Hepatocyte growth factor/scatter factor mediates angiogenesis through positive VEGF and negative thrombospondin 1 regulation. Proc Natl Acad Sci USA 100: 12718-12723, 2003.

8. Jeffers M, Fiscella M, Webb CP, Anver M, Koochekpour S and Vande Woude GF: The mutationally activated Met receptor mediates motility and metastasis. Proc Natl Acad Sci USA 95: 14417-14422, 1998.

9. Webb CP, Taylor GA, Jeffers M, et al: Evidence for a role of Met-HGF/SF during Ras-mediated tumorigenesis/metastasis. Oncogene 17: 2019-2025, 1998.

10. Gherardi E, Birchmeier W, Birchmeier C and Vande Woude G: Targeting MET in cancer: rationale and progress. Nat Rev Cancer 12: 89-103, 2012.

11. Nakajima M, Sawada H, Yamada Y, et al: The prognostic significance of amplification and overexpression of cMET and c-erb B-2 in human gastric carcinomas. Cancer 85: 1894-1902, 1999.

12. Lee J, Seo JW, Jun HJ, et al: Impact of MET amplification on gastric cancer: Possible roles as a novel prognostic marker and a potential therapeutic target. Oncol Rep 25: 1517-1524, 2011.

13. Tang Z, Zhao M, Ji J, et al: Overexpression of gastrin and cMET protein involved in human gastric carcinomas and intestinal metaplasia. Oncol Rep 11: 333-339, 2004.

14. Chen CT, Kim H, Liska D, Gao S, Christensen JG and Weiser MR: MET activation mediates resistance to lapatinib inhibition of HER2-amplified gastric cancer cells. Mol Cancer Ther 11: 660-669, 2012.

15. Kneissl J, Keller S, Lorber T, et al: Association of amphiregulin with the cetuximab sensitivity of gastric cancer cell lines. Int J Oncol 41: 733-744, 2012.

16. Oliner KD, Tang R, Anderson A, et al: Evaluation of MET pathway biomarkers in a phase II study of rilotumumab ( $R$, AMG 102) or placebo (P) in combination with epirubicin, cisplatin, and capecitabine (ECX) in patients (pts) with locally advanced or metastatic gastric (G) or esophagogastric junction (EGJ) cancer. Proc ASCO abs. 4005, 2012.

17. Catenacci DV, Henderson L, Xiao SY, et al: Durable complete response of metastatic gastric cancer with anti-Met therapy followed by resistance at recurrence. Cancer Discov 1: 573-579, 2011.

18. Cooper CS, Park M, Blair DG, et al: Molecular cloning of a new transforming gene from a chemically transformed human cell line. Nature 311: 29-33, 1984.

19. Park M, Dean M, Cooper CS, et al: Mechanism of met oncogene activation. Cell 45: 895-904, 1986.

20. Park M, Dean M, Kaul K, Braun MJ, Gonda MA and Vande Woude G: Sequence of MET protooncogene cDNA has features characteristic of the tyrosine kinase family of growth-factor receptors. Proc Natl Acad Sci USA 84: 6379-6383, 1987.

21. Bottaro DP, Rubin JS, Faletto DL, et al: Identification of the hepatocyte growth factor receptor as the cMET proto-oncogene product. Science 251: 802-804, 1991. 
22. Nakamura T, Nishizawa T, Hagiya M, et al: Molecular cloning and expression of human hepatocyte growth factor. Nature 342 : 440-443, 1989.

23. Stoker M, Gherardi E, Perryman M and Gray J: Scatter factor is a fibroblast-derived modulator of epithelial cell mobility. Nature 327: 239-242, 1987.

24. Peschard P and Park M: From Tpr-Met to Met, tumorigenesis and tubes. Oncogene 26: 1276-1285, 2007.

25. Ponzetto C, Bardelli A, Zhen Z, et al: A multifunctional docking site mediates signaling and transformation by the hepatocyte growth factor/scatter factor receptor family. Cell 77: 261-271, 1994.

26. Nguyen L, Holgado-Madruga M, Maroun C, et al: Association of the multisubstrate docking protein Gabl with the hepatocyte growth factor receptor requires a functional Grb2 binding site involving tyrosine 1356. J Biol Chem 272: 20811-20819, 1997.

27. Mughal A, Aslam HM, Khan AM, Saleem S, Umah R and Saleem M: Bcr-Abl tyrosine kinase inhibitors-current status. Infect Agent Cancer 8: 23, 2013.

28. Peters $S$ and Adjei AA: MET: a promising anticancer therapeutic target. Nat Rev Clin Oncol 9: 314-326, 2012.

29. Yamamoto N, Mammadova G, Song RX, Fukami Y and Sato K: Tyrosine phosphorylation of p145met mediated by EGFR and Src is required for serum-independent survival of human bladder carcinoma cells. J Cell Sci 119: 4623-4633, 2006.

30. Khoury H, Naujokas MA, Zuo D, et al: HGF converts ErbB2/ Neu epithelial morphogenesis to cell invasion. Mol Biol Cell 16: 550-561, 2005

31. Bauer TW, Somcio RJ, Fan F, et al: Regulatory role of cMET in insulin-like growth factor-I receptor-mediated migration and invasion of human pancreatic carcinoma cells. Mol Cancer Ther 5: 1676-1682, 2006

32. Uehara Y, Minowa O, Mori C, et al: Placental defect and embryonic lethality in mice lacking hepatocyte growth factor/ scatter factor. Nature 373: 702-705, 1995

33. Woolf AS, Kolatsi-Joannou M, Hardman P, et al: Roles of hepatocyte growth factor/scatter factor and the met receptor in the early development of the metanephros. J Cell Biol 128: 171-184, 1995.

34. Bladt F, Riethmacher D, Isenmann S, Aguzzi A and Birchmeier C: Essential role for the cMET receptor in the migration of myogenic precursor cells into the limb bud. Nature 376: 768-771, 1995.

35. Zhang YW and Vande Woude GF: HGF/SF-met signaling in the control of branching morphogenesis and invasion. J Cell Biochem 88: 408-417, 2003.

36. Chmielowiec J, Borowiak M, Morkel M, et al: cMET is essential for wound healing in the skin. J Cell Biol 177: 151-162, 2007.

37. Giordano S, Ponzetto C, Di Renzo MF, Cooper CS and Comoglio PM: Tyrosine kinase receptor indistinguishable from the cMET protein. Nature 339: 155-156, 1989.

38. Soman NR, Correa P, Ruiz BA and Wogan GN: The TPR-MET oncogenic rearrangement is present and expressed in human gastric carcinoma and precursor lesions. Proc Natl Acad Sci USA 88: 4892-4896, 1991.

39. Yu J, Miehlke S, Ebert MP, et al: Frequency of TPR-MET rearrangement in patients with gastric carcinoma and in first-degree relatives. Cancer 88: 1801-1806, 2000.

40. Lee HE, Kim MA, Lee HS, et al: MET in gastric carcinomas: comparison between protein expression and gene copy number and impact on clinical outcome. Br J Cancer 107: 325-333, 2012.

41. Janjigian YY, Tang LH, Coit DG, et al: MET expression and amplification in patients with localized gastric cancer. Cancer Epidemiol Biomarkers Prev 20: 1021-1027, 2011.

42. Retterspitz MF, Monig SP, Schreckenberg S, et al: Expression of \{beta\}-catenin, MUC1 and cMET in diffuse-type gastric carcinomas: correlations with tumour progression and prognosis. Anticancer Res 30: 4635-4641, 2010.

43. Park WS, Oh RR, Kim YS, et al: Absence of mutations in the kinase domain of the Met gene and frequent expression of Met and $\mathrm{HGF} / \mathrm{SF}$ protein in primary gastric carcinomas. APMIS 108: 195-200, 2000.

44. Tsugawa K, Yonemura Y, Hirono Y, et al: Amplification of the cMET, c-erbB-2 and epidermal growth factor receptor gene in human gastric cancers: correlation to clinical features. Oncology 55: 475-481, 1998.

45. Graziano F, Galluccio N, Lorenzini P, et al: Genetic activation of the MET pathway and prognosis of patients with high-risk, radically resected gastric cancer. J Clin Oncol 29: 4789-4795, 2011.
46. Shi J, Yao D, Liu W, et al: Frequent gene amplification predicts poor prognosis in gastric cancer. Int J Mol Sci 13: 4714-4726, 2012.

47. Schmidt L, Duh FM, Chen F, et al: Germline and somatic mutations in the tyrosine kinase domain of the MET proto-oncogene in papillary renal carcinomas. Nat Genet 16: 68-73, 1997.

48. Olivero M, Valente G, Bardelli A, et al: Novel mutation in the ATP-binding site of the MET oncogene tyrosine kinase in a HPRCC family. Int J Cancer 82: 640-643, 1999.

49. Lee JH, Han SU, Cho H, et al: A novel germ line juxtamembrane Met mutation in human gastric cancer. Oncogene 19: 4947-4953, 2000.

50. Asaoka Y, Tada M, Ikenoue T, et al: Gastric cancer cell line Hs746T harbors a splice site mutation of cMET causing juxtamembrane domain deletion. Biochem Biophys Res Commun 394: 1042-1046, 2010.

51. Burgess T, Coxon A, Meyer S, et al: Fully human monoclonal antibodies to hepatocyte growth factor with therapeutic potential against hepatocyte growth factor/cMET-dependent human tumors. Cancer Res 66: 1721-1729, 2006.

52. Jun HT, Sun J, Rex K, et al: AMG 102, a fully human antihepatocyte growth factor/scatter factor neutralizing antibody, enhances the efficacy of temozolomide or docetaxel in U-87 MG cells and xenografts. Clin Cancer Res 13: 6735-6742, 2007.

53. Gordon MS, Sweeney CS, Mendelson DS, et al: Safety, pharmacokinetics, and pharmacodynamics of AMG 102, a fully human hepatocyte growth factor-neutralizing monoclonal antibody, in a first-in-human study of patients with advanced solid tumors. Clin Cancer Res 16: 699-710, 2010.

54. Iveson T, Donehower RC, Davidenko I, et al: 6504 ORAL safety and efficacy of epirubicin, cisplatin, and capecitabine (ECX) plus rilotumumab (R) as first-line treatment for unresectable locally advanced (LA) or metastatic (M) gastric or esophagogastric junction (EGJ) adenocarcinoma. Eur J Cancer 47: S443, 2011.

55. First-line treatment for locally advanced or metastatic mesenchymal epithelial transition factor (MET)-positive gastric, lower esophageal, or gastroesophageal junction (GEJ) adenocarcinoma (RILOMET-1). http://www.clinicaltrials.gov/ct2/show/ NCT01697072. Accessed May 17, 2013.

56. MEGA (Met or EGFR inhibition in gastroesophageal adenocarcinoma): FOLFOX alone or in combination with AMG 102 or Panitumumab as first-line treatment in patients with advanced gastroesophageal adenocarcinoma. http://www.clinicaltrials.gov/ ct2/show/NCT01443065. Accessed May 17, 2013.

57. Martens T, Schmidt NO, Eckerich C, et al: A novel one-armed anti-cMET antibody inhibits glioblastoma growth in vivo. Clin Cancer Res 12: 6144-6152, 2006.

58. Penuel E, Li C, Parab V, et al: HGF as a Circulating biomarker of onartuzumab treatment in patients with advanced solid tumors. Mol Cancer Ther 12: 1122-1130, 2013

59. Jagoda EM, Lang L, Bhadrasetty V, et al: Immuno-PET of the hepatocyte growth factor receptor Met using the 1-armed antibody onartuzumab. J Nucl Med 53: 1592-1600, 2012.

60. A study of Onartuzumab (MetMAb) in combination with mFOLFOX6 in patients with metastatic HER2-negative gastroesophageal cancer. http://clinicaltrials.gov/ct2/show/ NCT01590719. Accessed May 15, 2013.

61. A study of Onartuzumab (MetMAb) in combination with mFOLFOX6 in patients with metastatic HER2-negative and Met-positive gastroesophageal cancer (MetGastric). http://www. clinicaltrials.gov/ct2/show/NCT01662869. Accessed May 15, 2013.

62. Munshi N, Jeay S, Li Y, et al: ARQ 197, a novel and selective inhibitor of the human cMET receptor tyrosine kinase with antitumor activity. Mol Cancer Ther 9: 1544-1553, 2010

63. Katayama R, Aoyama A, Yamori T, et al: Cytotoxic activity of tivantinib (ARQ 197) is not due solely to cMET inhibition. Cancer Res 73: 3087-3096, 2013.

64. Muro K, Ryu M-H, Yasui H, et al: A phase II study of tivantinib monotherapy in patients with previously treated advanced or recurrent gastric cancer. Proc ASCO abs.x 4082, 2012.

65. Phase I/II trial of Tivantinib with FOLFOX for the treatment of advanced solid tumors and previously untreated metastatic adenocarcinoma of the distal esophagus, gastroesophageal junction or stomach. http://www.clinicaltrials.gov/ct2/show/ NCT01611857. Accessed May 15, 2013.

66. Okamoto W, Okamoto I, Arao T, et al: Antitumor action of the MET tyrosine kinase inhibitor crizotinib (PF-02341066) in gastric cancer positive for MET amplification. Mol Cancer Ther 11: 1557-1564, 2012 
67. Lennerz JK, Kwak EL, Ackerman A, et al: MET amplification identifies a small and aggressive subgroup of esophagogastric adenocarcinoma with evidence of responsiveness to crizotinib. J Clin Oncol 29: 4803-4810, 2011.

68. Qian F, Engst S, Yamaguchi K, et al: Inhibition of tumor cell growth, invasion, and metastasis by EXEL-2880 (XL880, GSK1363089), a novel inhibitor of HGF and VEGF receptor tyrosine kinases. Cancer Res 69: 8009-8016, 2009.

69. Kataoka Y, Mukohara T, Tomioka H, et al: Foretinib (GSK1363089), a multi-kinase inhibitor of MET and VEGFRs, inhibits growth of gastric cancer cell lines by blocking interreceptor tyrosine kinase networks. Invest New Drugs 30: 1352-1360, 2012

70. Shah MA, Wainberg ZA, Catenacci DV, et al: Phase II study evaluating 2 dosing schedules of oral foretinib (GSK1363089), cMET/VEGFR2 inhibitor, in patients with metastatic gastric cancer. PLoS One 8: e54014, 2013.

71. Freidlin B, McShane LM, Polley MY and Korn EL: Randomized phase II trial designs with biomarkers. J Clin Oncol 30 3304-3309, 2012.

72. Yakes FM, Chen J, Tan J, et al: Cabozantinib (XL184), a novel MET and VEGFR2 inhibitor, simultaneously suppresses metastasis, angiogenesis, and tumor growth. Mol Cancer Ther 10 2298-2308, 2011

73. Schoffski P, Sgroi M, Burris HA, Lutzky J, Rearden T, Sikic B et al: Phase 2 randomized discontinuation trial (RDT) of XL184 in patients (pts) with advanced solid tumors. EORTC-NCI-AACR Symposium on Molecular Targets and Cancer Therapeutics. EJC Supplements 8: 117, 2010.

74. Kim MJ, Nam HJ, Kim HP, et al: OPB-31121, a novel small molecular inhibitor, disrupts the JAK2/STAT3 pathway and exhibits an antitumor activity in gastric cancer cells. Cancer Let 335: 145-152, 2013.

75. Oh D, Han S, Kim TM, et al: A phase I, open-label, nonrandomized trial of OPB-31121, a STAT3 inhibitor, in patients with advanced solid tumors. J Clin Oncol 28: e13056, 2010.

76. Camacho LH, Moulder SL, LoRusso PM, et al: First in human phase I study of MK-2461, a small molecule inhibitor of cMET, for patients with advanced solid tumors. J Clin Oncol 26 (Suppl 15): abs. 14657, 2008.

77. Falchook GS, Fu S, Amin HM, Piha-Paul SA, Hong DS, Naing A, et al: 1245 Poster Phase I dose-escalation study of the oral selective C-Met inhibitor EMD 1204831 in patients with advanced solid tumours. Eur J Cancer 47: S158, 2011.
78. Buchanan SG, Hendle J, Lee PS, et al: SGX523 is an exquisitely selective, ATP-competitive inhibitor of the MET receptor tyrosine kinase with antitumor activity in vivo. Mol Cancer Ther 8: 3181-3190, 2009

79. Awazu Y, Nakamura K, Mizutani A, et al: A Novel Inhibitor of cMET and VEGF Receptor Tyrosine Kinases with a Broad Spectrum of In Vivo Antitumor Activities. Mol Cancer Ther 12: 913-924, 2013

80. Oh YM, Song YJ, Lee SB, et al: A new anti-cMET antibody selected by a mechanism-based dual-screening method: therapeutic potential in cancer. Mol Cells 34: 523-529, 2012.

81. Nakagawa T, Tohyama O, Yamaguchi A, et al: E7050: a dual cMET and VEGFR-2 tyrosine kinase inhibitor promotes tumor regression and prolongs survival in mouse xenograft models. Cancer Sci 101: 210-215, 2010.

82. Goetsch L, Gonzalez A, Geronimi F, Fabre-Lafay S, et al: Single or combined in vivo therapies of cancer with h224G11, a humanized antibody targeting the cMET receptor. Mol Cancer Ther 8: B127, 2009.

83. Corso S, Ghiso E, Cepero V, et al: Activation of HER family members in gastric carcinoma cells mediates resistance to MET inhibition. Mol Cancer 9: 121, 2010.

84. Qi J, McTigue MA, Rogers A, et al: Multiple mutations and bypass mechanisms can contribute to development of acquired resistance to MET inhibitors. Cancer Res 71: 1081-1091, 2011.

85. Lee NV, Lira ME, Pavlicek A, et al: A novel SND1-BRAF fusion confers resistance to cMET inhibitor PF-04217903 in GTL16 cells through [corrected] MAPK activation. PLoS One 7: e39653, 2012.

86. Cepero V, Sierra JR, Corso S, et al: MET and KRAS gene amplification mediates acquired resistance to MET tyrosine kinase inhibitors. Cancer Res 70: 7580-7590, 2010.

87. Marangoni E, Vincent-Salomon A, Auger N, et al: A new model of patient tumor-derived breast cancer xenografts for preclinical assays. Clin Cancer Res 13: 3989-3998, 2007.

88. Amemiya H, Kono K, Mori Y, et al: High frequency of cMET expression in gastric cancers producing alpha-fetoprotein. Oncology 59: 145-151, 2000. 